\title{
Analysis of Energy Conservation on Application of Variable of Frequency Technology in Pump and Fan System in Power
}

\section{Plants}

\author{
Xinyue Guo \\ North China Electric Power University, Baoding 071000, China \\ 18331137177@163.com
}

\begin{abstract}
With the development of science and technology, energy has been widely applied in various kinds of fields. Some studies have shown that the pumps and fans' consumption of electricity is about $6.1 \%$ of the country's electricity generation annually. The problem of low efficiency is serious. Nowadays, power plants mainly use fixed mode. Desiring too large also makes the pumps and fans off the operating point easily, which low the efficiency and high the energy consumption. Depending on theoretical analysis and proof, it is shown that the frequency conversion technology can greatly improve the efficiency of pump and fan in this paper. Taking Chinese Dalian Development Zone Thermoelectric power plant's water pump and fan in Ruiming Power Plant for example, conclusions can be acquired. The frequency conversion technology can greatly improve the efficiency of the pump and the fan, and its application prospects in the power plant is very considerable.
\end{abstract}

Keywords: frequency conversion technology, pump and fan, plant, efficiency

\section{Introduction}

Energy industry plays an important role in national economy, and it makes people's life more convenient. However, how to economize energy has been a world-wide challenge. It has been shown that more than half of the $50 \mathrm{MW}$ pumps and fans in China are working at less than 70\% efficiency, and about one fifth of them are less than 50 percent efficient. [1] Therefore, it is of great significance to study the energy-saving technologies of pumps and fans in power plants to decrease heat loss. Frequency conversion technology is an outstanding energy-saving method that had been limited because of the immature technology and other factors in the past. With the improvement of frequency conversion technology, its reliability and economy has been increased greatly, which accelerates its extensive application.

\section{Principle}

AC asynchronous motors' power $\mathrm{P}$ and load torque $M_{L}$ can be expressed as

$$
P=M_{L} \bullet \omega
$$


Because of the relationship between load torque and angular velocity, the equation can be indicated as

$$
P \propto k \omega^{3}
$$

" $k$ "is a constant only related to the equipments. The frequency of electric motors is at a rate proportional to speed. Thus, frequency conversion technology is a means of changing speed, and the parameters of resource are variable.[2]

\section{Pump}

\subsection{Throttle regulation}

Throttle governing is a common used measure in power plants. Depending on whether throttle units installed on inlet line or outlet line, throttle governing can be divided into entrance throttle governing and export throttle governing, regulating the flow of the pipeline system by changing the opening degree.

The traditional way of regulating the pump is to regulate the water level by adjusting the door opening through the outlet of the pump.Fig. 1 presents the variation of pump head. The kinked line I is based upon a fully open valve, and operating point is $\mathrm{M}$. The kinked line II is under the conditions of a small valve opening. The increase of the local resistance coefficient of pipeline system makes the pipeline system performance curve becomes steep. The operating point changes from $\mathrm{M}$ to $\mathrm{A}$, and the flow rate decrease. The relationship between power and flow is

$$
P=\frac{\rho g q_{v}}{1000} k W .
$$

The throttle loss caused by the throttle valve is $h$, and the throttle loss power is

$$
\Delta P=\frac{\rho g q_{v} h}{1000} k W .
$$

The effective power and the axial power can be indicated as

$$
P_{e}=\frac{\rho g q_{v} H}{1000} \quad P_{s h}=\frac{\rho g q_{v}}{1000 \eta} .
$$

Thus, the operating efficiency of any point of the throttle adjustment is

$$
\eta_{j}=\frac{P_{e}-\Delta P}{P_{s h}}=\frac{(H-h)}{H} \eta .
$$

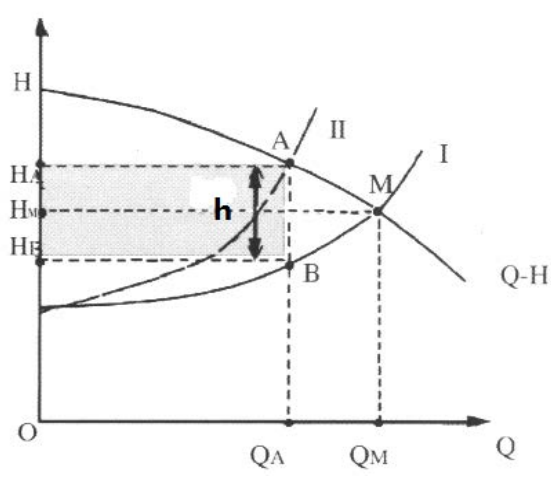

Figure 1.

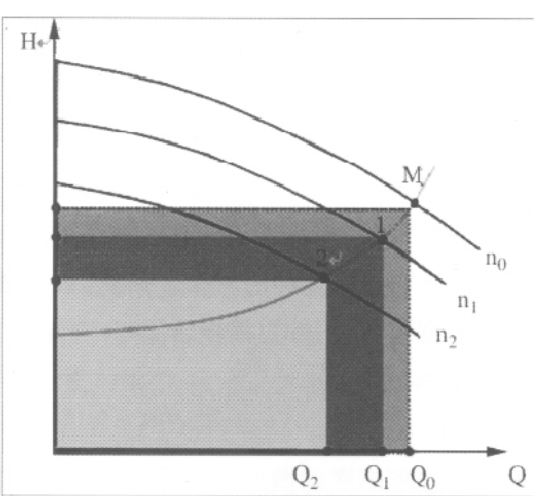

Figure 2. 


\subsection{Frequency conversion technology}

In the condition of fully opening the outlet valve, variable frequency control of condensate pump reduce the pump speed by changing the power supplied to the motor frequency. The pump characteristic curve Q-H would be moved down, and the operating point would be changed. With the decreasing of speed, the best operating point would change from $\mathrm{M}$ to2, and the flow rate and energy consumption would reduce.

Compare Figure 1 and Figure 2, it's obvious that throttle governing cost more energy than frequency conversion technology.

\subsection{Frequency conversion technology experiment}

Dalian Development Zone Thermal Power Plant has 3 sets of 220t/h high pressure boiler with two sets of 60MW pumping unit, equipping with 4 DG230-140 Feed water pumps. [3] Its main parameters are: flow rate 230t/h, raising capacity $1470 \mathrm{~m}$,power $1600 \mathrm{~kW}$, efficiency $75 \%$. By means of economical diagnostic test of water supply pump and pipeline system, it is found that its actual operation of the highest efficiency is $67.69 \%$, lower than the design value of $7.31 \%$.

According to field test, the frequency transformer of HARSVERT-A06/170 is available. External current source is used to control the output frequency of the frequency converter.

After a year of variable frequency operation, the maximum operating efficiency of the water pump is $79.4 \%$, and the water supply system minimum resistance to 0.9Mpa. It's overall energy saving effect is obvious.[4]

\section{Fan}

\subsection{Throttle governing}

Practice has proved that when use the export baffle to adjust the air volume, reducing the export baffle opening, the resistance increases. Not suitable for large-scale adjustment of air volume. When the low-speed area in the shaft power reduction is not much, energy-saving effect is not obvious. [5] If using the inlet baffle to control the air volume, although the adjustment range is wide and it reduces the baffle opening shaft power generally decreased with the wind down, its energy conservation effect is still lower than the frequency conversion technology. When using baffles to control air flow, although the operation requirement is satisfied, it causes a serious waste of energy, and equipment would easily damaged. So the throttle adjustment method does not apply to the fan.

\subsection{Frequency conversion technology}

According to the pump and fan similar law, when the motor speed or the fan speed is changed, if the efficiency is constant, the flow rate, head and speed have the flowing relationships.[6] 


$$
\begin{aligned}
& \frac{Q_{1}}{Q_{2}}=\frac{n_{2}}{n_{1}} \\
& \frac{H_{1}}{H_{2}}=\left(\frac{Q_{1}}{Q_{2}}\right)^{2}=\left(\frac{n_{2}}{n_{1}}\right)^{2} \\
& \frac{P_{2}}{P_{1}}=\left(\frac{Q_{1}}{Q_{2}}\right)^{3}=\left(\frac{n_{2}}{n_{1}}\right)^{3}
\end{aligned}
$$

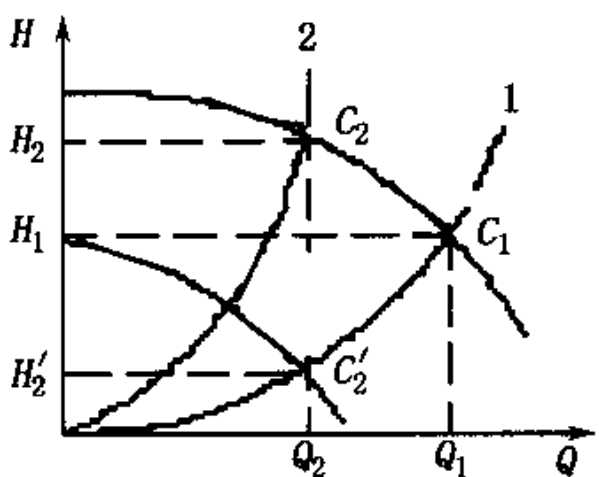

Fig.3.Fequency conversion technology

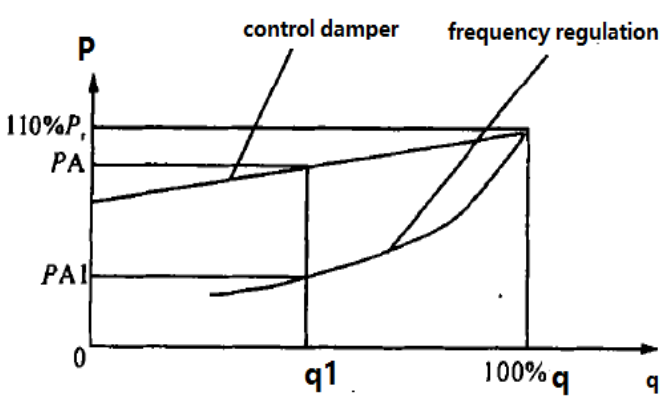

Fig.4.comparision of frequency conversion
technology and
control damper

The characteristic curve changes from 1 to 2 in figure3, and the operating point changes from $C_{1}$ to $C_{2}^{\prime}$.From figure4,we can know that when the flow rate is Q1,the power of the fan under control damper is PA and the power of the fan under frequency regulation is PA1. $\Delta \mathrm{P}=\mathrm{PA}$ - PA1.It is obvious that it has an excellent energy-saving effect.

\subsection{Frequency conversion technology experiment}

Ruiming Power Plant is equipped with two 125 MW units. Each boiler has two fans of JSQ1512-8. Its main parameters are: flow rate $41000 \mathrm{~m} 3 / \mathrm{h}$, raising capacity $1470 \mathrm{~m}$,power $700 \mathrm{~kW}$, speed $740 \mathrm{r} / \mathrm{min}$, rated voltage $6 \mathrm{kV}$, rated current $84.3 \mathrm{~A}$. Its No. 1 Boiler Fan originally use the inlet baffle throttle mode, and has the problem of high power consumption, noisy and high throttle loss [7]. Use the series of ZINVERT to transmit the No. 1 Boiler. After a month of operating, compare the energy-saving efficient.

\section{Conclusion}

Based on theoretical analysis and experiment, the final conclusion is available. Frequency conversion technology makes the pump and fan system operate on the demands, which high the efficiency and reduce the cost. The frequency conversion technology is most ideal plan of motor speed control. The frequency conversion technology has a splendid future with the rapid development of China's electric power, electronics, control technology and its reliability. 


\section{References}

[1] Xu Yong, Yuhua Chen, Xiaohong Xia et al. Application of Condensate Pump Frequency Conversion Technology in Energy Saving of Power Plant [J]

[2] Zhang Ming. The Applied research of High-voltage variable frequency speed regulation and energy saving technology on the condensate pump [D]. 2014,3

[3] Zhao Bin, Guiqiang Mo. Application of frequency conversion governor in energy saving reformation of boiler [J]. Electric Power of Guangxi, 2003.03

[4] Tengniang Ding, Liangfa Xie, Shaoqu Liang. Application of Variable Frequency Technology in Boiler Induced Draft Fan and Energy Saving Analysis.[J]. Guangdong Electric Power, 2007,6

[5] Yanjia, Wanghui. Study on Energy Saving of Frequency Conversion Technology in Pump and Fan System of Power Plant.[A]. R\&D. 2012

[6] Guizhong Wu. Application and Evaluation of Frequency Conversion Technology Transformation Project in Thermal Power Plant in Dalian Development.[D]. 2010.4.12

[7] Yade Wu. Study on Energy Saving of Pump and Fan in Power Plant.[J]. Industrial Technology. 2012.02 